\title{
Forgotten War: Democractic Republic of the Congo
}

$\mathrm{F}$

ve world-renowned photographers from the VII Photo Agency - Ron Haviv, Gary Knight, Antonin Kratochvil, Joachim Ladefoged and James Nachtwey - travelled to the Democratic Republic of Congo (DRC) from May through August of 2005 with the international humanitarian organization Médecins Sans Frontières/ Doctors Without Borders (MSF) in order to shed light on the suffering of the Congolese people as they struggle to survive a war that remains virtually invisible to the outside world. Their work is presented in Democratic Republic of the Congo: Forgotten War, a photo exhibition and a new book published by de.MO. The exhibition had its launch in New York last September and has since toured the DRC, Japan, Switzerland, Denmark, Canada and Hong Kong.
Over a decade of war and the collapse of the public health system have resulted in widespread and acute misery for people throughout the DRC. Many Congolese face extreme deprivation and violence, with brutal militia attacks and sexual violence common. Severe malnutrition and epidemics of diseases like malaria, HIV/AIDS and cholera take an even greater toll as few people have access to health facilities, let alone treatment. The complex and diverse nature of the violence and neglect challenges any notion of simple, blanket solutions to address even the immediate causes of so much death and suffering. (c) Ron Haviv/VII

- Daily life at the Bon Marché Hospital. Médecins Sans Frontières/Doctors Without Borders (MSF) runs the 330bed hospital free of charge to those in need from Bunia and the Ituri region. The government-run hospital in town lacks proper facilities and charges people for healthcare. More than 3.8 million people have died in the Congo conflict since 1998. The majority of people die from disease and hunger.

Internally Displaced People (IDP) at the Tche camp in the eastern part of the Ituri province. The people from the Hema tribe fled their homes after attacks in January 2005.

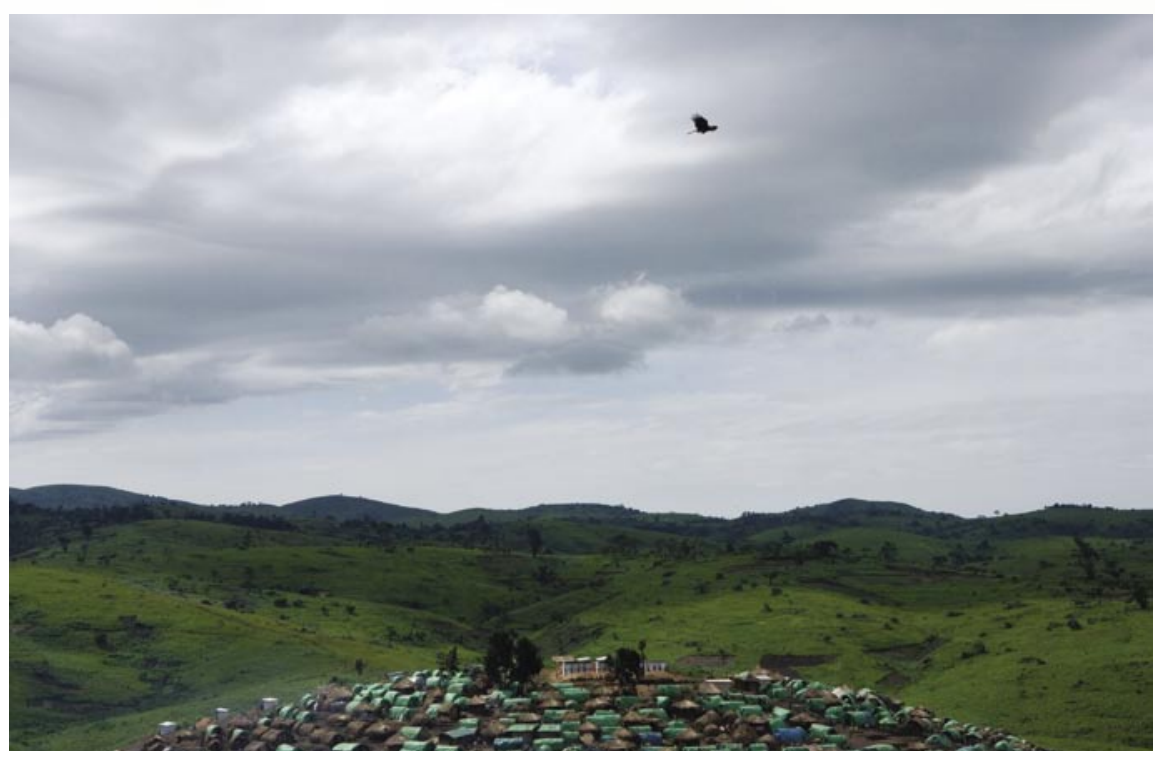


